\title{
Uma análise do direito ao território tradicional Panambi Lagoa Rica dos Guarani-Kaiowá em Mato Grosso do Sul sob a perspectiva da constituição de 1988
}

\author{
Julia Thais Moraes ${ }^{1}$
}

Silvia Dettmer Araujo²

\begin{abstract}
Resumo: O presente trabalho visa analisar o direito ao território tradicional Panambi Lagoa Rica dos Guarani-Kaiowá, em Mato Grosso do Sul. Nessa análise, busca-se demonstrar como se configurou a dispersão territorial protagonizada por essas etnias mediante a criação de reservas indígenas a partir da atuação do Serviço de Proteção ao Índio (SPI), entre 1915 a 1928. Dentre os motivos que estruturam as reservas indígenas citam-se os interesses coloniais e agrários em virtude de integrarem a diáspora indígena no Estado. Coloca-se que por razões históricas, a terra Panambi Lagoa Rica se torna um direito inerente ao território tradicional. Destaca-se que a decisão judicial que reconhecia o território como território indígena foi anulada, no ano de 2016, não efetivando assim, esse direito constitucional, acarretando o enfraquecimento dos laços territoriais étnicos. Diante desse contexto, este estudo se fundamenta na dispersão territorial indígena, a fim de justificar o direito ao território tradicional. Aplica-se à pesquisa o método exploratório, bibliográfico e qualitativo no convívio com o texto constitucional de 1988.
\end{abstract}

Palavras-chave: Dispersão territorial étnica. Direito ao território tradicional Panambi Lagoa Rica. GuaraniKaiowá.

\section{An analysis of the right to the traditional territory Panambi lagoa rica dos Guarani- Kaiowá in Mato Grosso do Sul under the perspective of the constitution of 1988}

\begin{abstract}
The present work aims at analyzing the right to the traditional Panambi Lagoa Rica of the Guarani-Kaiowá, in Mato Grosso do Sul. This analysis seeks to demonstrate how the territorial dispersion carried out by these ethnic groups was created through the creation of indigenous reserves SPI) between 1915 and 1928. Among the reasons that structure the indigenous reservations are the colonial and agrarian interests, due to the integration of the indigenous diaspora in the State. It is stated that for historical reasons, that Panambi land Lagoa Rica becomes an inherent right to the traditional territory. It should be noted that the judicial decision recognizing the territory as indigenous territory was annulled in 2016, thus failing to implement this constitutional right, leading to a weakening of ethnic territorial ties. Given this context, this study is based on the indigenous territorial dispersion, in order to justify the right to the traditional territory. The exploratory, bibliographic and qualitative method used in the study of the 1988 constitutional text is applied to the research.
\end{abstract}

Keywords: Guarani-Kaiowá. Right to the traditional territory Panambi Lagoa Rica. Ethnic territorial dispersion.

\section{introdução}

A palavra kaiowá é oriunda do termo $k a^{\prime}$ agua, que no dialeto guarani determina uma comunidade que vive na mata. Na esfera internacional, encontra-se esse termo traduzido para o espanhol e elencado em documentos de demarcação de terras indígenas como os Tratados de Madri (1750) e Santo Ildefonso (1778).

Em Mato Grosso do Sul, os sertanistas do século XXI grafaram a variação da expressão kaiowá, que se encontrava em quatro termos, caiua, caigua, caioas, cayuas e cayuaz (CHAMORRO, 2016, p. 209-210). Atualmente se emprega kaiowá como termo para a autoidentificação, que consiste na noção de pertencimento individual a determinada etnia. 
Considera-se que as etnias guarani-kaiowá pertencem à família linguística tupi-guarani. A etnia guarani se denomina Nadeva, enquanto a Kaiowá Pai-Tavytera: "habitantes do povoado do centro da terra" (CHAMORRO, 2016, p. 209).

Quanto a sua localização topográfica, essas etnias ocupavam um extenso território no Estado de MS entre o rio Apa, Serra de Maracaju, os rios Brilhante, Ivinhema, Paraná, Iguatemi e a fronteira com o Paraguai. Agrupavam-se em áreas de mata, ao longo dos córregos e rios, em pequenas comunidades de uma ou duas famílias (BRAND, 2004, p. 138).

$\mathrm{O}$ projeto de aldeamento indígena foi estabelecido no território nacional desde o período imperial (CAVALCANTE, 2012, p. 12), destacando-se nas províncias ${ }^{3}$ que não possuíam áreas exploradas e colonizadas. Iniciado na década de 1840 pelo Barão de Antonina

Em 1850, o Barão elaborou a Lei de Terras, que objetivava contratar sertanistas para demarcar glebas para suas fazendas. Legislação considerada como precursora na organização da propriedade privada no país.

Com isso, em 1863 os trabalhos da fundação do aldeamento Indígena Antonina foram iniciados, associando-se a colônia militar de Dourados (CHAMORRO, 2016, p. 217-218).

A expulsão dos indígenas Guarani-kaiowá se articulou a partir de 1880, após a guerra do Paraguai, quando a Companhia Matte Laranjeira (1882) instalou-se na região. A companhia deslocou um grande contingente populacional indígena, cuja mão de obra nos ervais era predominantemente indígena, exercidas em jornadas de trabalho exaustivas.

Com base nas considerações de Chamorro (2016, p. 221), observa-se que uma das consequências deste período para a população Kaiowá foi o fim definitivo do isolamento, uma vez que os exploradores já não eram viajantes e forasteiros. A exploração da erva-mate acarretou o surgimento de novos núcleos populacionais e novas cidades, como Porto Murtinho, Bela Vista, São Tomás, Nhu Verá, Campanário, Caracol, Margarida, Cabeceira do Apa e Porto Felicidade.

Elucida ainda que nesse contexto, o trabalho indígena passou a ser cada vez mais requisitado e que a desorganização social foi outro saldo desta época. A exploração da erva era uma atividade rotativa e muitos indígenas se ausentavam por longos períodos dos seus locais tradicionais de residência, acampando isolados ou com suas famílias nos ranchos das ervateiras.

Após o término do processamento da erva no local, o rancho e os trabalhadores mudavam de lugar ou estes últimos mudavam de patrão (ARRUDA, 1997, p. 61).

Para Chamorro (2016, p. 221) esta mobilidade forçada dispersou as comunidades indígenas e perturbou as suas formas de produção, consumo e sociabilidade tradicionais. A tuberculose e as epidemias de varíola e sarampo ceifaram tantas vidas, que a Missão Evangélica Caiuá chegou a construir a Ñanderóga, 'Nossa Casa', para acolher crianças, sobretudo, órfãs.

Diante desse cenário, o Serviço de Proteção ao Índio (SP) atuante entre 1915 a 1928 demarcou oito reservas indígenas que objetivavam aglomerar a diversidade populacional étnica dispersas no território sul do atual Estado de Mato Grosso do Sul, antiga província nomeada Mato Grosso.

Essas reservas representavam políticas estatais de liberação de terras destinadas à colonização e subjugação indígena aos projetos de apropriação e exploração de recursos naturais pelo homem branco.

As demarcações de reservas indígenas elaboradas pelo Estado buscavam dirimir os conflitos exploratórios dos indígenas pelos ervateiros. No entanto, as reservas se tornaram centros de ne- 
gociação da mão de obra indígenas. Assim, institucionalizou-se a exploração econômica de terras indígenas não demarcadas, mas que eram povoadas por eles (CHAMORRO, 2016, p. 222).

A Colônia Agrícola Federal de Dourados (Decreto-lei n. 5.941) estruturada em 1943 sinalizou a marcha colonial para o oeste em que os colonos, inicialmente ocupariam apenas áreas não habitadas pelos índios. Entretanto essa prerrogativa não foi cumprida e culminou na dispersão dos indígenas que se encontravam naquela região.

Em 1948 se iniciou a negociação para delimitar uma área mínima que pudesse garantir a sobrevivência dos Guarani-kaiowá da região. Em 1950 restaram aos indígenas sete lotes da Colônia Agrícola Federal de Dourados (CAND).

Os sete lotes da colônia corroboravam o processo de expropriação territorial e a transferência compulsória dos grupos para dentro das pequenas reservas previamente criadas naquele exíguo território; gerou também a expulsão dos indígenas de áreas colonizadas.

No relatório da Inspetoria Regional, Iridiano Amarinho de Oliveira, na carta ao Diretor do SPI em dezembro de 1952, atestou-se a invasão do território Panambi Lagoa Rica por parte da Colônia Agrícola Nacional de Dourados (Brasil, Relatório da Comissão Nacional da Verdade, 2014, p. $222-$ 223) e, consequentemente, a expulsão dos guarani-kaiowá.

A partir da década de 1950, a instalação de empreendimentos agropecuários em outros espaços ocupados pelos guarani-kaiowá expandiu-se acentuando o processo de desmatamento e dispersão do territorial.

Em 1970, a soja e a mecanização da produtividade agrícola adentraram a região povoada por indígenas, em contrapartida a mão-de-obra indígena foi dispensada. A substituição dos restos de mata, capoeiras e campos pela monocultura da soja, comprometeu a biodiversidade, essencial para o modelo guarani-kaiowá.

Neste sentido, Brand aduz que (2004, p. 140-141)

O comprometimento dos recursos naturais, resultante da perda da terra, retirou as condições
necessárias para a sua economia, impondo aos homens indígenas o assalariamento.
Provocou a rápida passagem de alternativas variadas de subsistência - agricultura, caça,
pesca e coleta - para uma única alternativa, a agricultura e esta apoiada em poucas
variedades de cultivares e, mais recentemente, o assalariamento em usinas de álcool.
No entanto, mais do que as alternativas econômicas, comprometeu de forma crescente
a autonomia interna desses povos por reduzir suas possibilidades de decisão sobre essas
questões, deixando cada vez um espaço mais reduzido para a negociação a partir de suas
alternativas históricas culturais.

A partir de 1978 o movimento indígena guarani-kaiowá se organiza para reivindicar a posse de terras tradicionais, elegendo como alicerce do movimento a dispersão territorial forçosa iniciada no século XXI, por atos estatais.

\section{Ocupação territorial indígena}

O conceito de terra tradicional é construído através do elemento da tradicionalidade de uma ocupação indígena em determinada área. É o elemento apresentado pela Constituição Federal de 1988, que consiste nos modos de ocupação territorial dos índios (CARNEIRO DA CUNHA, 2009, p. 283), especificamente no: 
Art. $231 \S 1^{\text {o: }}$ São terras tradicionalmente ocupadas pelos índios as por eles habitadas em caráter permanente, as utilizadas para suas atividades produtivas, as imprescindíveis à preservação dos recursos ambientais necessários a seu bem-estar e as necessárias a sua reprodução física e cultural, segundo seus usos, costumes e tradições (BRASIL, Constituição Federal de 1988).

Esclarece-se que a tradicionalidade abrange quatro pressupostos inerentes ao local ocupado, que são os recursos naturais necessários ao bem-estar, usos costumes e tradições. Estes se relacionam diretamente com o território, em virtude de este espaço proporcionar a reprodução física e cultural indígena (HOBSBAWM, 2008, p. 9).

Nesse sentido, a Constituição de 1988 ressalta a noção de território ligado aos processos socioculturais indígenas realizados naquela área ocupada. Assim a terra indígena deve ser apta ao exercício sustentável e regular uma ocupação tradicional. Isto é a utilização do território segundo “seus usos e costumes" (PACHECO DE OLIVEIRA, 1999, p. 111).

Justifica-se assim, o critério adotado para substituir uma identificação meramente normativa por uma identificação fundada no aspecto cultural que circunda determinada área tradicional, resultando na compreensão da importância do território a organização indígena.

\section{PROCEDIMENTO PARA DEMARCAÇÃO DE TERRAS INDÍGENAS}

A Constituição Federal em seu artigo 231 prevê aos índios o direito a posse permanente e usufruto exclusivo das terras que ocupam, determinando ser de competência da União à demarcação e proteção.

O decreto $\mathrm{n}^{\circ} 1.775 / 96$ dispõe sobre o procedimento administrativo de demarcação das terras indígenas e dá outras providências. Inicia elencando que as terras indígenas, de que tratam o art. 17, I, da Lei $n^{\circ}$ 6001, de 19 de dezembro de 1973, e o art. 231 da Constituição, serão administrativamente demarcadas por iniciativa e sob a orientação do órgão federal de assistência ao índio, de acordo com o disposto no texto do decreto citado.

A demarcação das terras tradicionalmente ocupadas pelos índios será fundamentada em trabalhos desenvolvidos por antropólogo de qualificação reconhecida, que elaborará, em prazo fixado na portaria de nomeação baixada pelo titular do órgão federal de assistência ao índio, estudo antropológico de identificação.

O órgão federal de assistência ao índio designará grupo técnico especializado, composto preferencialmente por servidores do próprio quadro funcional, coordenado por antropólogo, com a finalidade de realizar estudos complementares de natureza etno-histórica, sociológica, jurídica, cartográfica, ambiental e o levantamento fundiário necessário à delimitação.

O grupo indígena envolvido, representado segundo suas formas próprias, participará do procedimento em todas as suas fases. O grupo técnico solicitará, quando for o caso, a colaboração de membros da comunidade científica ou de outros órgãos públicos para embasar os estudos complementares mencionados no parágrafo anterior.

Concluídos os trabalhos de identificação e delimitação, o grupo técnico apresentará relatório circunstanciado ao órgão federal de assistência ao índio (FUNAI), caracterizando a terra indígena a ser demarcada. De acordo com a Portaria n ${ }^{\circ}$ 14, de 09/01/96, o relatório deverá possuir dados gerais 
como: informações gerais sobre os grupos indígenas envolvidos, filiação cultural e linguística e as características da terra indígena a ser demarcada.

Aprovado o relatório pelo titular do órgão federal de assistência ao índio, este fará publicar, no prazo de quinze dias contados da data que o receber, o resumo do mesmo no Diário Oficial da União e no Diário Oficial da unidade federada onde se localizar a área sob demarcação, acompanhado de memorial descritivo e mapa da área, devendo a publicação ser afixada na sede da Prefeitura Municipal da situação do imóvel.

Desde o início do procedimento demarcatório até noventa dias após a publicação, poderão os Estados e Municípios em que se localize a área sob demarcação e demais interessados manifestar-se, apresentando ao órgão federal de assistência ao índio razões instruídas com todas as provas pertinentes, tais como títulos dominiais, laudos periciais, pareceres, declarações de testemunhas, fotografias e mapas, para o fim de pleitear indenização ou para demonstrar vícios, totais ou parciais, do relatório de que trata o parágrafo anterior. Esse prazo para contestação objetiva pleitear indenização ou demonstrar vícios existentes no relatório.

A partir da contestação a FUNAI tem 60 diais para elaborar pareceres sobre as razões de todos os interessados e encaminhar o procedimento para o Ministro da Justiça. Terminado este procedimento haverá as declarações dos limites da terra Indígena.

Cabe mencionar que é de competência do Ministro da Justiça em 30 dias expedir portaria declarando os limites da área e determinando a sua demarcação física; ou prescrever diligências que julgar necessárias, as quais deverão ser cumpridas em mais 90 dias. Decidirá ainda desaprovando a identificação e retornando os autos ao órgão federal de assistência ao índio, mediante decisão fundamentada, circunscrita ao não atendimento do disposto no $\S 1^{\circ}$ do art. 231 da Constituição e demais disposições pertinentes.

A FUNAI após a declaração dos limites territoriais da área indígena promove a sua demarcação física e ao Instituto Nacional de Colonização e Reforma Agrária (INCRA), cabe proceder ao reassentamento de eventuais ocupantes não índios.

Por fim, o procedimento de demarcação deve ser submetido ao Presidente da República para homologação por decreto. A terra demarcada e homologada será registrada, em até 30 dias após a homologação, no Cartório de Imóveis da comarca correspondente e na Secretária de Patrimônio da União.

\section{A demarcação da terra indígena Panambi Lagoa Rica/MS}

O território Panambi Lagoa Rica, em Mato Grosso do Sul é povoado pelas etnias guaranikaiowá cujo povoamento ocorreu em razão do processo histórico de dispersão causado pelas políticas estatais de aldeamento e pela ocupação de fazendas em terras indígenas.

O espaço territorial Panambi Lagoa Rica se estruturou a partir da instalação dos guarani-kaiowá nas margens de lagoas e nascentes próximas ao córrego Panambi. Na segunda metade da década de 1970, a porção norte da aldeia foi efetivamente ocupada, com um ambiente menos exuberante, raras nascentes e um solo menos fértil, deixando o povo confinado a uma área de 366 hectares, sem matas, matérias-primas ou animais de médio porte. 
Ressalta-se que a área Panambi Lagoa Rica denominada GuyraKambi’y, possui 12.196 hectares de extensão e foi identificada como terra indígena pela Fundação Nacional do Índio (FUNAI) em 2011.

O resumo do relatório circunstanciado de identificação e delimitação da terra indígena concluiu que a área ocupada tradicionalmente pelos indígenas guarani-kaiowá apresenta condições ambientais necessárias às atividades produtivas desenvolvidas pelas etnias. Destacou o aspecto do bem-estar e das necessidades de reprodução física e cultural deste povo, segundo seus usos, costumes e tradições, em conformidade com o artigo 231 da Constituição Federal vigente.

Neste sentido, os estudos se fundamentaram nos elementos objetivos de natureza etno-histórica, antropológica, ambiental, documental, cartográfica e fundiária.

\section{A decisão judicial sobre a terra indígena Panambi Lagoa Rica/MS}

Em outubro de 2016 a demarcação da terra indígena Panambi Lagoa Rica foi anulada por uma sentença judicial em Dourados. A decisão proferida pelo juiz federal Moisés Anderson Costa Rodrigues da Silva, da $1^{\text {a }}$ Vara Federal de Dourados (MS), declarou nulo o processo de demarcação da área delimitada em 2011.

O fundamento utilizado pelo magistrado para anular a demarcação foi à tese do marco temporal. Essa tese restringe o reconhecimento de terras indígenas apenas àquelas que eram ocupadas pelos índios na data da promulgação da Constituição Federal, em 5 de outubro de 1988. A exceção ocorre nos casos em que a comunidade tenha sofrido esbulho de seu território e expulsa. ${ }^{4}$

A sentença não apenas empregou tese do marco temporal, como também recuperou uma interpretação restritiva da ideia de renitente esbulho, aplicada pelo ministro Teorí Zavascki em um julgamento do Supremo Tribunal Federal (STF). Esse julgamento anulou a homologação da terra indígena Limão Verde, do povo Terena, também em Mato Grosso do Sul, em março de 2015.

Segundo a interpretação restritiva do renitente dada pelo ministro Teorí Zavascki, o esbulho é a exceção que não permite aplicar o marco de 5 de outubro de 1988. Sendo passível de aplicação apenas se os indígenas estivessem em conflito efetivo ou movendo uma ação na Justiça contra os fazendeiros na exata data de promulgação da $\mathrm{CF} / 88$. Infere-se que a decisão de Zavascki não é vinculante e a sua aplicação a outros casos poderá gerar mais conflitos no campo.

Nas palavras do Ministro, o renitente esbulho consiste no real conflito possessório iniciado no passado e persistente até o marco demarcatório temporal da data da promulgação da Constituição de 1988, materializado por circunstâncias de fato ou por controvérsia possessória judicializada.

Observa-se que várias comunidades indígenas estão enfrentando decisões de primeira e segunda instância fundamentadas na tese do marco temporal, como exemplo da terra indígena Guyraroka que também teve terra de ocupação anulada pelo Supremo Tribunal Federal.

Diante da natureza constitucional dos direitos dos índios verifica-se o questionamento advindo de juristas, organizações indígenas e indigenistas, que encontrou no parecer jurídico de José Afonso da Silva uma resposta sintética perante a inquietação nas comunidades indígenas. 


\section{A comprovação do esbulho indígena configurando o direito a demarcação da terra Panambi Lagoa Rica}

A área de ocupação tradicional Panambi Lagoa Rica passou a ser estudada pela FUNAI em 2005 e os estudos de identificação e delimitação da área de 12.196 hectares levaram mais de dez anos para serem publicados pelo órgão.

O relatório final que fundamentou a portaria do presidente da FUNAI ao reconhecer a tradicionalidade da ocupação nessa área, reuniu vasta documentação histórica e trabalho em campo. Documentos atestavam que as terras incluídas no município de Douradina até a década de 1940 eram ocupadas exclusivamente pelos guarani-kaiowá desde o século XIX (PEREIRA, 2004, p. 116). O esbulho é comprovado pela Colônia Agrícola Nacional de Dourados, que permitiu a invasão colonial da área de ocupação tradicional.

O histórico recuperado no relatório da Comissão Nacional da Verdade 2014 reconheceu o processo de expulsão dos indígenas de suas terras como grave violação a direitos fundamentais. Segundo o relatório há documentos do SPI (1946-1947), que mostram que os guarani-kaiowá da região entre Dourados e Rio Brilhante comunicavam-se reiteradamente com o SPI para pedir auxílio diante do avanço dos colonos, sem obter sucesso ${ }^{5}$.

Na década de 1950, o decreto presidencial reconheceu aos índios apenas sete lotes da Colônia Agrícola (BRAND, 2004, p. 289). Com isso as reclamações aos órgãos indigenistas continuaram insistentemente pelas décadas seguintes, quando a invasão de suas terras por fazendeiros se consolidou. Entende-se que, diante dos acontecimentos, a tese do esbulho renitente seja mais favorável aos índios por se apresentar em consonância com os direitos constitucionais.

\section{Conclusão}

Os fatos históricos comprovam a dispersão territorial indígena. Tal movimento não coaduna com a ideia de que os indígenas têm um dinamismo cultural diferente e entrelaçado à formação do povo brasileiro desde o período colonial.

As etnias guarani-kaiowá que povoam o território Panambi Lagoa Rica não devem ter desconsideradas a sua organização social, costumes, línguas, crenças e tradições no qual suas representações indígenas estão sendo produzidas e que são salvaguardadas pelo texto constitucional.

A territorialidade se faz necessária à organização social dos índios que são sujeitos ativos históricos e que clamam pela observação as suas comunidades, diversidades e culturas nas terras tradicionalmente habitadas.

A anulação pela via judicial da área indígena Panambi Lagoa Rica, em Mato Grosso do Sul frente a todo procedimento legal cumprido, relembra as ações pretéritas que destituíram territórios que pertenciam aos indígenas. Demonstra ainda uma resistência em acolher dados históricos e documentais recolhidos pelo relatório da FUNAI que foram favoráveis a demarcação da terra como indígena.

O Decreto 1.775/96 é o instrumento que dispõe sobre o procedimento de demarcação das terras indígenas, porém, diante de um tema emblemático como esse, torna-se impossível abordar 
a problemática instigante e complexa de maneira exaustiva. Buscou-se assim, apresentar algumas reflexões sobre o direito indígena que vem se constituindo um grande desafio no meio jurídico.

\section{Notas}

1 Mestranda BOLSISTA CAPES/PROSUP em Teoria Geral do Direito pelo Centro Universitário de Marília UNIVEM 2019/2021 . Graduada em Direito ( 2014/2018) na Universidade Federal de Mato Grosso do Sul/ UFMS-CPTL. Atua na área de direito constitucional, especificamente em direitos fundamentais relacionados ao contexto indígena, e também na esfera de direitos humanos integrado com direitos Indígenas. E-mail: juliamoraes094@outlook.com

2 Professora Adjunta da UFMS, campus de Três Lagoas. Desde 2004 é lotada no corpo docente do curso de Direito da UFMS/CPTL na disciplina de Direito Constitucional. Graduada em Direito pela Fundação Eurípides Soares da Rocha de Marília/SP (UNIVEM) e Mestrado em Direito Constitucional pela Instituição Toledo de Ensino, de Bauru/SP. Doutora em Direito Constitucional pela PUC/SP. E-mail: silviadettmer@ globo.com

3Há regulamentações com força de lei - as Cartas Régias, o Diretório dos Índios, o Regulamento das Missões de 1845 etc., relatórios provinciais, correspondências trocadas entre missionários e diretores dos aldeamentos e as autoridades coloniais ou imperiais e, com menor freqüência, documentos jurídicos como processos e requerimentos ou petições envolvendo os grupos indígenas aldeados.

4 Disponível em: http://www.ihu.unisinos.br/560862-um-ano-apos-ataques-juiz-anula-demarcacao-de-terra-dos-guarani-kaiowa-ms. Acesso em: 04 jun. 2017.

5 Disponível em: http://www.mpf.mp.br/atuacao-tematica/ccr6/documentos-e-publicacoes/artigos/docs_artigos/jose-afonso-da-silva-parecer-maio-2016-1.pdf. Acesso em: 01 mai. 2017.

\section{Referências}

ARAÚJO, Ana Valéria et alii. Povos Indígenas e a Lei dos "Brancos": o direito à diferença. Brasília, MEC/ SECAD - LACED/Museu Nacional, 2006

ARRUDA, Gilmar. Frutos da terra: os trabalhadores da Mate Laranjeira. Londrina: Eduel, 1997.

ARRUDA, Lucybeth Camargo de. Posto Fraternidade Indígena: Estratégias de civilização e táticas de resistência (1913-1945). Dissertação de Mestrado em História/UFMT. Cuiabá, 2003.

ALMEIDA, Paulo Roberto de. A estrutura constitucional das relações internacionais e o sistema político brasileiro. Contexto Internacional, Rio de Janeiro, n. 12, jul./dez. 1990.

ALMEIDA, Fernanda Dias Menezes de. Competências na Constituição de 1988. $2^{\mathrm{a}}$ ed. São Paulo: Atlas, 2000.

BARCELLOS, Ana Paula de. A eficácia jurídica dos princípios constitucionais - o princípio da dignidade da pessoa humana. Rio de Janeiro: Renovar, 2002.

BARBIERI, S. R. J. Os Direitos Constitucionais dos Índios e o direito a diferença, face ao princípio da dignidade da pessoa humana. Coimbra: Almedina, 2008.

BOBBIO, Norberto. Igualdade e Liberdade. 31 a ed. Rio de Janeiro: Ediouro, 2001.

BOGDANDY, Arminvon; ANTONIAZZI, Mariela Morales; PIOVESAN, Flávia (coord.). Direitos humanos, democracia e integração jurídica na América do Sul. Rio de Janeiro: Lúmen Juris, 2010.

BRAND, Antônio. Os complexos caminhos da luta pela terra entre os Kaiowa e Guarani no MS. Revista Tellusano 4, n.6. Campo Grande: 2004, p. 138. Disponível em: http://www.gpec.ucdb.br/projetos/tellus/ index.php/tellus/article/view/82. Acesso em: 22 mai. 17. 
BRASIL. Constituição da República Federativa do Brasil de 1988. Disponível em: http://www.planalto.gov.br/ccivil_03/constituicao/constitui\%C3\%A7ao.htm. BRASIL.

. FUNAI Disponível em: http://www.funai.gov.br/indios/conteudo.htm. Acesso em 10 mai. 2017.

Lei que dispõe sobre o procedimento administrativo de demarcação das terras indígenas e dá outras providências. Disponível em: http://www.planalto.gov.br/ccivil 03/decreto/D1775.htm. Acesso em: 10 mai. 2017.

. Demarcação de terras. Disponível em: http://www.ihu.unisinos.br/560862-um-ano-apos-ataques-juiz-anula-demarcacao-de-terra-dos-guarani-kaiowa-ms. Acesso: 04 jun. 2017.

MPF. Disponível em: http://www.mpf.mp.br/atuacao-tematica/ccr6/documentos-e-publicacoes/ artigos/docs_artigos/jose-afonso-da-silva-parecer-maio-2016-1.pdf. Acesso em: 01 mai. 2017.

CAVALCANTE, Thiago Leandro Vieira. Os Guarani e Kaiowá na fronteira entre o Brasil e o Paraguai: etnicidades e nacionalidades, implicações quanto ao acesso a direitos. In: XIV Jornadas Internacionales sobre las Misiones Jesuíticas, 2012, San Ignacio de Velasco. XIV Jornadas Internacionales... San Ignacio de Velasco: Universidad Católica Boliviana - Chiquitos, 2012. v. 1. p. 1-16.

CARNEIRO DA CUNHA, Manuela. Os Direitos do Índio: Ensaios e Documentos. São Paulo: Brasiliense, 1987. p. $97-108$

. Etnicidade: da cultura residual, mas irredutivel. In: Antropologia do Brasil. São Paulo: Brasiliense. Introdução a uma história indígena. In: História dos índios no Brasil. São Paulo:

Companhia das Letras, 1992.

CANOTILHO, Gomes. Direito Constitucional e Teoria da Constituição, $7^{\mathrm{a}}$ ed, 2003

CANÇADO TRINDADE, Antônio Augusto; ROBLES, Manuel E. Ventura. El futuro de la Corte Interamericana de Derechos Humanos. $2^{\mathrm{a}}$ ed. atualizada e ampliada. San José/Costa Rica: Corte Interamericana de Direitos Humanos/ ACNUR, 2004.

. A interação entre o direito internacional e o direito interno na proteção dos direitos humanos.

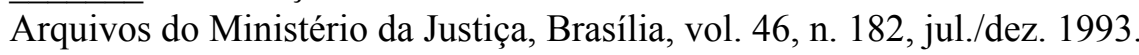

CHAMORRO, Graciela. Povos indígenas guarani falantes no atual Estado de Mato Grosso do Sul (Séculos XVI-XXI), pp. 209-210, Disponível em: http://200.144.182.130/cema/images/Graciela_Chamorro_Povos indigenas guarani falantes no atual_Estado_de Mato_Grosso_do_Sul.pdf. Acesso em: 10 mai. 17.

FARIA, Gustavo. A verdade sobre o indio brasileiro. Guavirá editores, 2000.

FERNANDES, B. G. A. Curso de Direito Constitucional. Salvador: Juspodivm, 2014.

GOMES, Mércio Pereira. O Índio na História: o povo Tenetehara em busca da liberdade. Petrópolis: Vozes, 2002.

GONÇALVES, Wagner. Terras de Ocupação Tradicional: Aspectos Práticos da Perícia Antropológica. In. SILVA, O. S.; LUZ, L. \& VIEIRA, C. M. (Orgs.) A perícia antropológica em processos judiciais. Florianópolis: Ed. Da UFSC, 1994.

HOBSBAWM, Eric. Introdução: A Invenção das Tradições. In. HOBSBAWM, E \& RANGER, T. A invenção das tradições. $6^{\text {a }}$ ed. São Paulo: Paz e Terra, 2008.

. Nações e Nacionalismo desde 1780: programa, mito e realidade. Rio de Janeiro: Paz e Terra, 1990

HOLANDA, Sérgio Buarque de. Raízes do Brasil. 2. ed., revista e ampliada. Rio de Janeiro, 2014.

MARTINS. Tatiana Azambuja Ujacow. Direito ao pão novo: o principio da dignidade humana e a efetivação do direito indígena. São Paulo: Editora Pilhares, 2005 
MOREIRA da Silva Lásaro, O modelo integracionista de tutela indigena e sua incompatibilidade com a Constituição. In: SOUSA JUNIOR, São Paulo: Saraiva, 2015.

NE-MOISÉS, Claudia.A internacionalização dos direitos humanos: Constituição, racismo e relações internacionais. São Paulo: Manole, 2005.

PEREIRA, Levi Marques. O movimento étnico-social pela demarcação das terras guarani em MS. Tellus, Campo Grande, v. 3, n. 4, p. 137-145, abr. 2003.

PIOVESAN, F. Direitos Humanos e o Direito Constitucional Internacional. São Paulo: Saraiva, 2015.

PORANTIM. Em defesa da causa indígena. Ano XXVIII - nº 239 - Brasília DF. Março,2007.

PIRES, M. I. C. A Guerra dos Bárbaros. 1. ed. Recife: Editora Universitária, 2002. v. 1.

RAMOS, A. R. Constituições nacionais e povos indígenas. Belo Horizonte: UFMG. Editora, 2012.

RIBEIRO, Darcy. O Povo brasileiro, a formação e o sentido do Brasil. $3^{\text {a }}$ ed. Global, 2015

SARMENTO, Daniel. A Dimensão Objetiva dos Direitos Fundamentais: fragmentos de uma teoria. Arquivos de Direitos Humanos. Rio de Janeiro: Lumen Juris, 2002.

SARMENTO, Daniel; IKAWA, Daniela; PIOVESAN, Flávia. Direitos humanos, igualdade e diferença. Rio de Janeiro: Lumen Juris, 2008.

SANTILLI, Márcio. Os Brasileiros e os Índios. São Paulo: SENAC, 2000.

SAQUET, Marcos Aurélio. Abordagens e Concepções de Território. São Paulo: Expressão Popular, 2007.

SILVA, Fernanda Duarte Lopes Lucas. Princípio Constitucional da Igualdade. Rio de Janeiro: Lúmen Juris: Rio de Janeiro, 2005.

SILVA, José Afonso da. Curso de direito constitucional positivo. São Paulo: Malheiros, 2011.

SOUZA, José Otávio Catafesto. Mobilização indígena, direitos originários e cidadania tutelada no sul do Brasil depois de 1988" In Fonseca, Claudia; Terto Jr., Veriano \& Alves, Caleb Farias (orgs.) Antropologia, Diversidade e Direitos humanos: diálogos interdisciplinares. Porto Alegre, URFGS, 2004: p. 185-197

LEITÃO, Sérgio - Os Direitos Constitucionais dos Povos Indígenas - 2003

LIMA, E. V. D. Estatuto do Índio. 3. ed. Salvador: Juspodivm, 2016. v. 1. 394p

LOBO, Luiz Felipe Bruno. Direito Indigenista Brasileiro. São Paulo: LTr, 1996.

VILLARES, Luiz Fernando. Direito e povos indígenas. Curitiba: Juruá, 2009.

WOLKMER, Antônio Carlos. Os Novos Direitos no Brasil: Natureza e perspectivas: uma visão básica das novas conflituosidades jurídicas. São Paulo: Saraiva 2003. 